\title{
Pelvic inflammatory disease by actinomyces: report of 1 case and review of the literature
}

\author{
Cesar Giovanni Camacho Herrera ${ }^{1 *}$, Raul D. Lara Sanchez ${ }^{1}$, Narmy Olivera Garcia ${ }^{2}$, \\ Karla E. Abundiz Bibiano ${ }^{3}$
}

\begin{abstract}
${ }^{1}$ Resident, Department of Gynecology and Obstetrics, Postgraduate School of Naval Health, Naval Medical Center, Secretariat of the Navy of Mexico (SEMAR), Mexico

${ }^{2}$ Department of Obstetrics and Gynecology, Colposcopist, Attached to The Naval Medical Center, Navy Secretary of Mexico

${ }^{3}$ Resident, Department of Radiology and Image, Naval Health Postgraduate School, Naval Medical Center; Secretariat of the Navy of Mexico (SEMAR), Mexico
\end{abstract}

Received: 08 November 2019

Revised: 05 January 2020

Accepted: 09 January 2020

\section{*Correspondence:}

Dr. Cesar Giovanni Camacho Herrera,

E-mail: camacho_galan60@ hotmail.com

Copyright: (C) the author(s), publisher and licensee Medip Academy. This is an open-access article distributed under the terms of the Creative Commons Attribution Non-Commercial License, which permits unrestricted non-commercial use, distribution, and reproduction in any medium, provided the original work is properly cited.

\begin{abstract}
Actinomycosis is a chronic disease that is characterized by the formation of abscesses, fistulas and dense fibrous tissue at the site of involvement. Its distribution is worldwide. However, pelvic actinomycosis has increased in frequency and has been associated with abdominal surgery, intestinal perforation or trauma, due to the destruction of the muscular barrier. The clinical elements of suspicion are the latency of months and even years of symptoms and the history of being a carrier of an intrauterine device. Actinomyces israelli is a rare etiological agent of pelvic inflammatory disease, so it is difficult to reach the diagnosis. A case report is made of a 48-year-old patient with an intrauterine device older than 5 years, who entered the emergency department with abdominal pain syndrome and 7day evolutionary fever accompanied by dyspareunia. She was hospitalized for antibiotic treatment, presenting an unsatisfactory evolution, with increased leukocytosis and persistent abdominal pain. An exploratory laparotomy with abdominal hysterectomy was performed. The histopathological diagnosis was pelvic inflammatory disease due to actinomyces. We must always suspect in the presence of a pelvic inflammatory disease in any of its clinical forms, the presence of actinomyces as one of the possible causative germs, especially in patients with intrauterine device for more than 5 years.
\end{abstract}

Keywords: Abdominal actinomycosis, Abdominal pain, Actinomycosis, Actinomyces israelli, Dyspareunia, Pelvic actinomyces, Pelvic inflammatory disease

\section{INTRODUCTION}

Pelvic inflammatory disease is a set of symptoms and signs that respond to an inflammatory disorder of the female genital tract, ranging from endometritis, salpingitis, salpingooforitis, septic tube-ovarian abscesses, septic pelviperitonitis and shock that would compromise the patient's life. At present, all women of childbearing and sexually active age should be suspected, it is more frequent and aggressive in adolescence. ${ }^{1,2}$

In 1979, Cowgill conducted a review of cases of pelvic inflammatory disease by actinomyces for 40 years, reporting a total of 300 cases. $^{3}$ Two thirds corresponded 
to the abdominal cavity, especially of appendicular origin. Increasing the frequency of pelvic infection, which is attributed to the massive use of intrauterine devices. The first report of ovarian actinomyces was published in 1909 by Taylor and Fisher. ${ }^{4}$ In 1966 Figueroa et al, they presented the case of a patient with an intrauterine device operated by a bilateral ovarian tube abscess with the presence of actinomyces Israelii. ${ }^{5}$

The relationship between genital colonization by Actinomyces, the use of intrauterine devices and the development of pelvic inflammatory disease has been well analyzed from the work of Henderson in 1973, who was the first to describe this association. ${ }^{6}$ Since then there have been numerous publications of cases of genital actinomycosis in women who carry intrauterine devices, which confirm that this intrauterine foreign body predisposes to the genital tract superior to infection or increases the virulence of actinomyces. ${ }^{7}$ In addition, it has been proven that the risk is greater with the use of plastic devices than with those of copper and especially in cases where their use continues for more than three years. ${ }^{8}$

In 1976, Actinomyces was first identified in Pap smears, which allowed its use as a method of detection in IUD users to be postulated. ${ }^{9}$

A study published in 1987 a review of cervicovaginal cytology smears of 1400 women using IUDs was performed, which showed $12.6 \%$ colonization, with a risk clearly related to the time of use of the device. ${ }^{10}$

Fiorino published an incidence range of 0 to $31 \%$ with an average of $71 \%$ in women using IUDs and with cervicovaginal cytology positive for Actinomyces. ${ }^{11}$

Actinomyces Israelii is a saprophytic bacterium that is usually found in the oral cavity and in the tonsil crypts. ${ }^{12}$ Poor oral hygiene is a predisposing factor. Which from the oral cavity can reach the respiratory or digestive tract mainly affecting the appendix. Once the mucosa is penetrated, dissemination occurs by continuity, destroying the anatomical planes. Rarely there are distant foci by hematogenous dissemination. The lymphatic route is considered exceptional. As bacteria proliferate, they spread to neighboring tissues and form a fibrotic mass. Typically, the microorganism masses form granules with abundant eosinophils, which are called "sulfur grains". ${ }^{13}$ The microbiological technique of choice is by demonstration of sulfur grains by deep tissue aspiration by needle. The microscopy grains are white, between 50 and $400 \mu \mathrm{m}$ in size. ${ }^{14}$

There may be secondary fibrosis, which produces areas of induration, which is confused with neo-malignant formation. With hematoxylin and eosin staining, the lesions show a mixed inflammatory infiltrate with formation of micro abscesses, nuclear polymorphs, central necrosis, multilobed grains, and presence of basophils.
The culture should be carried out under anaerobic conditions between 35-37 degrees Celsius, in chocolate agar. The colonies develop between 5 and 15 days and are yellow white. ${ }^{15}$

Penicillin is the drug of choice; resistance is rare high doses should be administered for prolonged times. ${ }^{19}$ In those who are allergic to penicillin, options include tetracyclines, erythromycin, doxycycline and clindamycin. However, the response to tetracyclines and ciprofloxacin is poor and a beta-lactam antibiotic combined with a beta-lactamase inhibitor should be the first option. ${ }^{16}$

Parenteral therapy may be required for a severe infection before switching to the oral route. In general, the disease is treated until there is evidence of complete resolution. Occasionally, surgery is required to drain the abscesses, but since the actinomyx infection does not respect the tissue planes, the surgery can be complicated and, if possible, should be delayed at least until after a cycle of antibiotic use. ${ }^{16}$

\section{CASE REPORT}

34-year-old woman originally and resident of the state of Mexico, Catholic, active military. No chronic degenerative history denied allergies, transfusions. Smoking from the age of 15 at the rate of 2-3 cigarettes a day. irregular menstrual, with dysmenorrhea. Beginning of active sexual life at age 16; number of sexual partners 4. Methods of family planning, user of intrauterine device for 5 years to the present. Last cervicovaginal cytology 9 months ago negative to malignancy. Gestas 1 caesarean section 1 in 2008 for preeclampsia.

Go to the emergency department for presenting abdominal pain in hypogastric medical assessment where ciprofloxacin and gentamicin were administered for 7 days due to urinary tract infection; During more than 2 weeks of evolution, attending this service by not showing clinical improvement and exacerbation of abdominal pain and fever, he decided to go to the hospital. It also refers to a history of constipation of 3 days of evolution and pain in the lumbar back region.

On the physical examination, the following vital signs are detected: Blood pressure of 120/60 mmhg; Heart rate of 80 beats per minute; $96 \%$ oxygen saturation; Respiratory rate of 20 breaths per minute; temperature of $36{ }^{\circ} \mathrm{C}$. It is conscious, oriented, adequate coloration, cardiopulmonary without apparent commitment. Globose abdomen due to adipose panicle, decreased intensity in peristalsis, deep palpation pain at hypogastric level, negative rebound, no data from peritoneal irritation, no appendicular data. Giordano positive of predominance right. Normal genitals, to the vaginal uterus touch in Anteroversoflexion of approximately $9 \times 10 \mathrm{~cm}$, pain due to mobilization of the cervix. Eutermic cavity, glove with non-fetid whitish leukorrhea. 
Table 1: Laboratory studies.

\begin{tabular}{|llllllll|}
\hline DATE & LEUC & NEUT & HB & HTO & PLT & VSG & PCR \\
\hline 06.01 .19 & $16.1 \mathrm{mil}$ & $82.7 \%$ & $9 \mathrm{Gr} / \mathrm{dl}$ & $28.4 \%$ & 704000 & $40 \mathrm{~mm}$ & $23.2 \mathrm{mg} / \mathrm{dl}$ \\
\hline 07.01 .19 & $15.6 \mathrm{mil}$ & $81 \%$ & $8.6 \mathrm{Gr} / \mathrm{dl}$ & $27 \%$ & 624000 & $36 \mathrm{~mm}$ & $18 \mathrm{mg} / \mathrm{dl}$ \\
\hline 09.01 .19 & $16.4 \mathrm{mil}$ & $85 \%$ & $8.1 \mathrm{Gr} / \mathrm{dl}$ & $26 \%$ & 663000 & $32 \mathrm{~mm}$ & $18.99 \mathrm{mg} / \mathrm{dl}$ \\
\hline $\begin{array}{l}\text { HB: Hemoglobin, LEUC: Leukocytes, HTO: Hematocrit, PLT: Platelets, VSG: } \\
\text { protein }\end{array}$
\end{tabular}

Spectroscopy shows vaginal walls without apparent lesions, whitish secretion not fetid in the posterior sac, observing IUD guides at the level of the cervical orifice, which is removed without incident, taking vaginal cultures. Extremities without edema, rest not alterations. Laboratory studies are annexed in Table 1. He was hospitalized as pelvic inflammatory disease and pyelonephritis; Renal ultrasound showing bilateral renal inflammatory process.

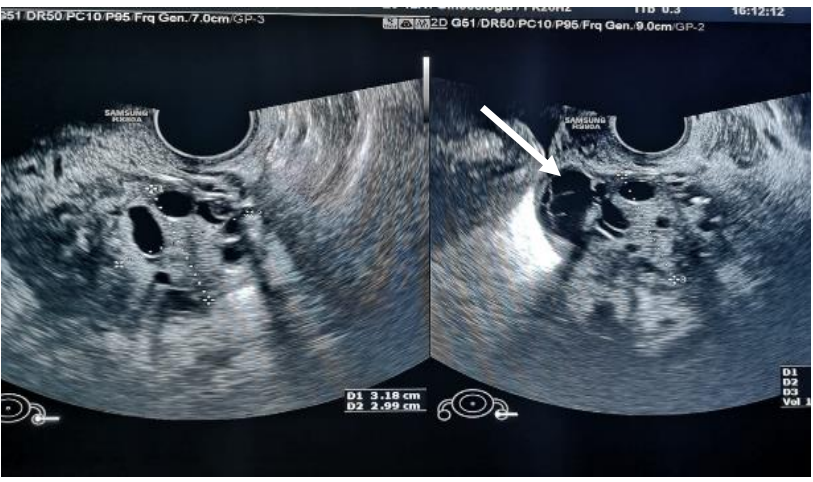

Figure 1: Transvaginal ultrasound. Left ovary with presence of follicles, as well as peripheral free fluid with some septa.

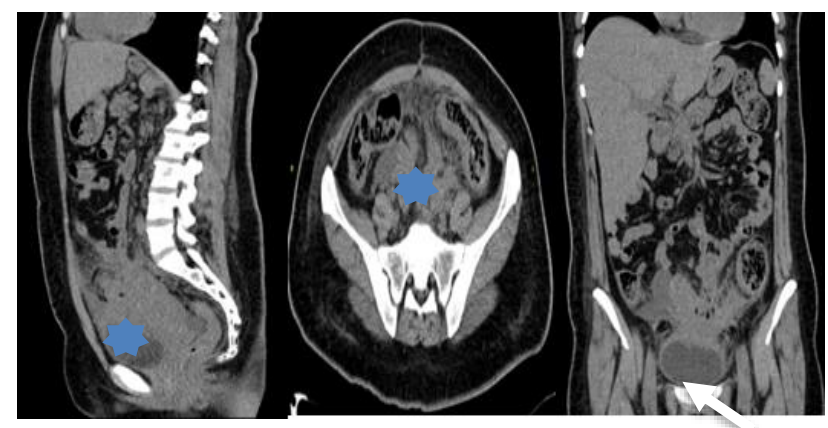

Figure 2: Simple abdominal tomography sagittal, coronal and axial. It is displayed at the level of the pelvic hollow, striation of the mesenteric fat, without adequate visualization of the annexes and uterine cavity (asterisk), as well as thickening of the bladder wall and the colonial path at the level of its sigmoid portion (arrow).

Transvaginal ultrasound (Figure 1) with presence of peripheral free fluid with some septa and simple cyst of left ovary.
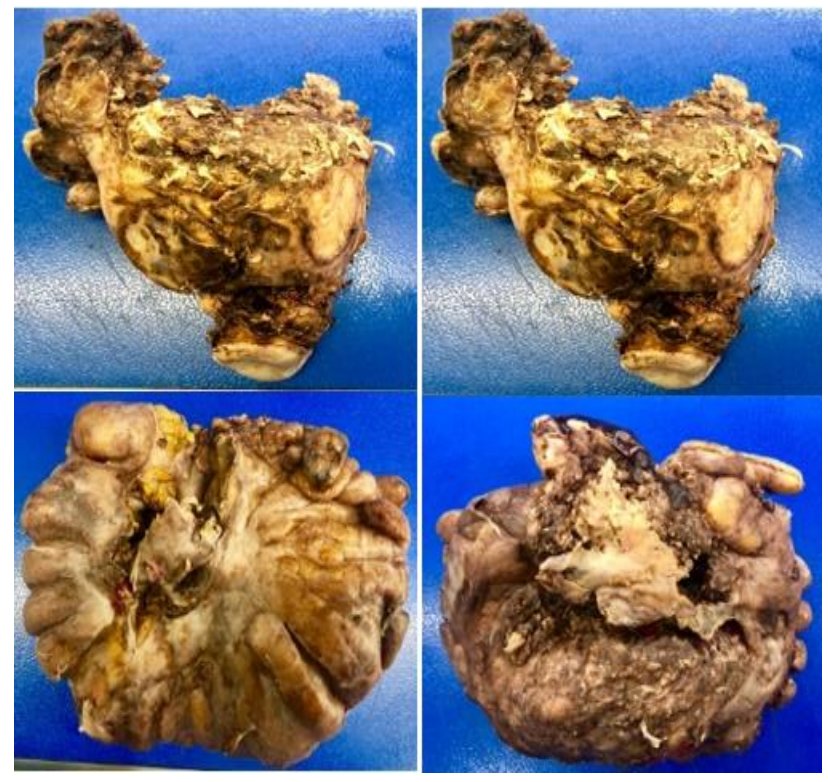

Figure 3: Macroscopic appearance of the uterus and sigmoid colon segment. External surface with abundant fibrinous material and adhesions.

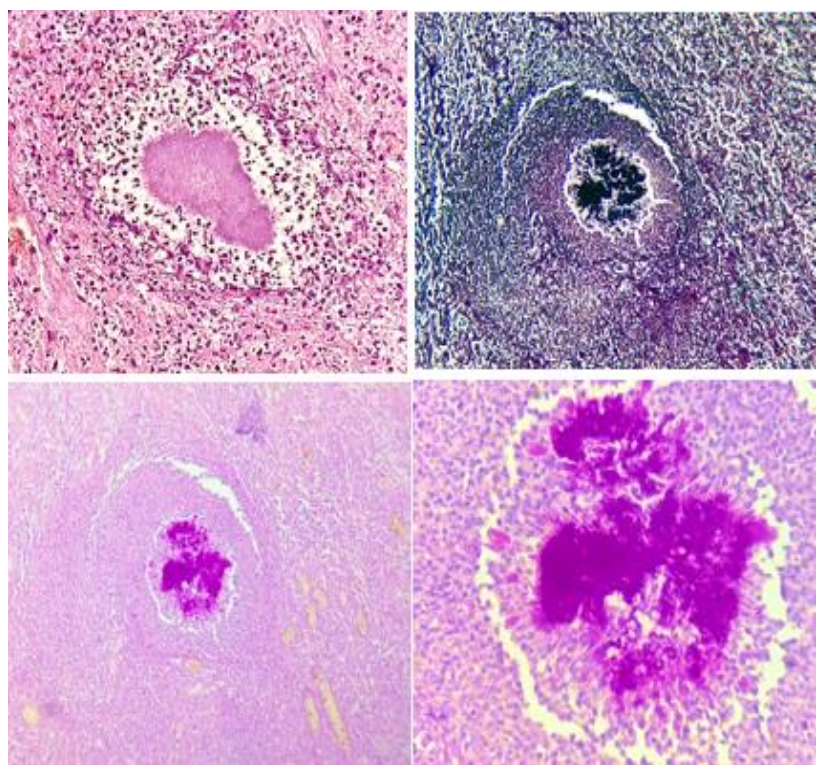

Figure 4: The histopathological study showed the presence of Actinomyces surrounded by abundant acute and chronic inflammatory infiltrate. With hematoxylin and eosin, 10x; Grocott, 4x; PAS, 4x and PAS, 40x. 
Treatment based on levofloxacin was initiated, presenting a torpid evolution even persisting with fever, leukocytosis and malaise; Simple pelvic abominated tomography was requested (Figure 2) which reported striation of mesenteric fat and thickening of the bladder wall, reporting complicated pelvic inflammatory disease

An exploratory laparotomy was performed; finding of multiple adhesions epiploon - uterus, tumor that encompasses the sigmoid rectum that involves bladder and uterus. Interconsultation was performed with the general surgery and oncological surgery service which performed posterior pelvic exenteration with preservation of the right ovary, pelvic peritonectomy, partial omentectomy, primary bladder closure, right JJ placement, descending colon colostomy, right paravesical biopsy. Negative trans-operative report to malignancy.

During the surgical procedure, the following findings were found: $10 \times 6 \mathrm{~cm}$ sigmoid colon tumor, with left pelvic wall carciomatosis, an enlarged uterus firmly attached to the bladder, $4 \times 4 \mathrm{~cm}$ right paravesical tumor (Figure 3), pelvic actinomycetic histopathological report (Figure 4).

\section{DISCUSSION}

Pelvic inflammatory disease due to actinomyces has ceased to be infrequent, so it should be suspected in every woman of childbearing and sexually active age, in this case the prolonged use of the intrauterine device was a predisposing factor for the presence of the germ and the appearance of the pelvic abscess (pelvic actinomycosis) that caused extensive fibrosis in adjacent organs, conditioning diagnostic discrepancy.

Pelvic actinomycosis constitutes $3 \%$ of all actinomycotic infections in humans, mainly causing endometritis, salpingooforitis and tube-ovarian abscesses; About $80 \%$ of cases of these infections have been described in women who used the IUD for a long time (more than 4 years). It is considered as a risk factor in young women.

The clinical symptoms are not very specific and include a wide range of clinical presentations such as fever, minimal and non-existent pain, weight loss, inflammation where the infectious focus occurs and abscesses, which leads to frequent errors in the diagnosis with other pathological conditions such as diverticulitis, ulcerative colitis, Crohn's disease, tuberculosis, inflammatory bowel disease and malignant tumors. In most cases the diagnosis of pelvic inflammatory disease caused by Actinomyces is performed post-surgery after the microbiological and pathological findings that evidence this microorganism. Regarding treatment, penicillin is the treatment of choice, since resistance to it is rare, and high doses can be given for prolonged courses. ${ }^{13}$ There are other therapeutic options such as tetracycline, erythromycin, clindamycin, and the combination of a beta-lactam with a beta-lactamase inhibitor may be the first option. However, the response to tetracyclines and ciprofloxacin is poor. In most cases, the diagnosis of pelvic inflammatory disease caused by Actinomyces is performed after surgery after the microbiological and pathological findings that evidence this microorganism.

\section{ACKNOWLEDGMENTS}

The authors thank the medical and logistic team of the Naval Medical Center, Mexico City for the facilities provided with respect to the patient's medical history. Likewise, the medical and technical personnel who contributed to the diagnosis and treatment of the patient are thanked.

\section{Funding: No funding sources \\ Conflict of interest: None declared \\ Ethical approval: Not required}

\section{REFERENCES}

1. Trevino Salinas EM, Martinez Palones JM, Perez Benavente MA. Pelvic Actinomycosis in menopaysal patient,case review. Ginecol Obstet Mex. 2003;71:532-6.

2. Madrid S, Freddy Díaz Z, Francisco, Klaassen, Rodrigo. Gynecological actinomycosis. Chilean J Obstet Gynecol. 2003;68(1):21-7.

3. Cowgill R, Quan S. Colonic actinomycosis mimicking carcinoma. Colon Rectum. 1979;22:45-6.

4. Wells W, Campodónico I, Gunther A, Ried A. Actinomycosis of the female genital tract. Rev Chil Obstet Ginecol. 1980;45:141-6.

5. Figueroa Y. Actinomicosis anexial. Rev Chil Obstet Ginecol. 1966;31:391.

6. Henderson S. Pelvic actinomycosis associated with an IUD. Obstet Ginecol. 1973;41:726-32.

7. Keebler C, Chatwani A, Schwartz R. Actinomycosis infection associated with intrauterine device. Am J Obstet Gynecol. 1983;145(5):596-9.

8. Fawzi MC, Lambert W, Singler JM. Factors associated with forced sex among women accesing health services in rural Haiti. implications for the prevention of HIV infections and other sexually transmitted diseases. Soc Sci Med. 2005;60(4):67989.

9. Ross JD. European guideline for the management of pelvic inflammatory disease and perihepatitis. Int $\mathbf{J}$ STD AIDS. 2001;12(Suppl 3):84-7.

10. Alegría J, González P, Galleguillos M, Whittle C, Franco C. Review of pelvic infection by Actinomyces. Presentation of a clinical case. Rev Chil Radiol. 2003;9(4):196-200.

11. Bustos-Moya G, Josa-Montero D, Perea-Ronco J, Gualtero-Trujillo S. Pelvic inflammatory disease by Actinomyces sp. in a patient with an intrauterine device: a case report. Infection. 2016;20(1):33-6.

12. Maxoma X, Menzlova E, Kolarik D, Dundr P, Halaska M. Case report: pelvic actinomicosis. Prague Medical Rep. 2012;113(1):44-8. 
13. Koo YJ, Kwon YS, Shim JU, Mok JE. Predictors associated with severity of pelvic actinomycosis. J. Obstet. Gynaecol Res. 2011;37(12):1792-6.

14. Iwasaki M, Nishikawa A, Akutagawa N, Fujimoto T, Teramoto M, Kudo R. A case of ovarian actinomicosis. Infect Dis Obstet Gynecol. 2003;11(3):171-3.

15. Pusiol T, Morichetti D, Pedrazzani C, Ricci F. Abdominal-pelvic actinomycosis mimicking malignant neoplasm. Infect Dis Obstet Gynecol. $2011 ; 2011$.
16. Smith AJ, Hall V, Thakker B, Gemmell CG. Antimicrobial susceptibility testing of Actinomyces species with 12 antimicrobial agents. J Antimicrobial Chemother. 2005;56(2):407-9.

Cite this article as: Herrera CGC, Sanchez RDL, Garcia NO, Bibiano KEA. Pelvic inflammatory disease by actinomyces: report of 1 case and review of the literature. Int J Reprod Contracept Obstet Gynecol 2020;9:804-8. 